\title{
Defining Data-Driven Analytical Methods on Improving Energy-Efficiency in Apartment Buildings †
}

\author{
Timo Ruohomäki *, Andreas Andra and Kimmo Raivio \\ Forum Virium Helsinki Oy, 00130 Helsinki, Finland; email1@gmail.com (A.A.); email2@gmail.com (K.R.) \\ * Correspondence: timo.ruohomaki@forumvirium.fi \\ + Presented at the 7th International Electronic Conference on Sensors and Applications, 15-30 November \\ 2020; Available online: https://ecsa-7.sciforum.net/.
}

Published: 15 November 2020

\begin{abstract}
Energy efficiency is one of the key characteristics of the smart cities and data-driven analytical methods, especially including IoT sensors, meaningful indicators are provided to support the leading of initiatives but also behavior changing in the citizen level. The analysis is oftentimes done in closed systems that contain sensors, data acquisition, analysis and visualization. To improve effectiveness of energy efficiency initiatives in climate programs, harmonization of analytical methods and quality assurance of the data is required. This paper provides an overview of these themes based on the findings from two EU-funded projects, ERDF 6Aika Climate Friendly Housing Companies and H2020 mySMARTLife.
\end{abstract}

Keywords: IoT; sensor data quality; energy efficiency; optimization

\section{Introduction}

Heating of the properties generates 56 percent of the carbon emissions in the city of Helsinki [1]. Privately owned and rental properties have seen relatively few improvements in energy efficiency in recent years and as part of their climate programs, the cities look for initiatives and incentives to tackle the issue. Reasons for the lack of action in rental properties may also be a range of market barriers and market failures including misinformation, split incentives and an uneven power dynamic between renters and landlords.

Finland has quite a rare model on the way how the private buildings are formed as a single legal body that owns the apartments. Instead of owning an apartment as a property, the right to hold the apartment is given by owning shares in the limited liability housing company. This structure may sometimes affect decision making on not only investments but also all the spending, including consulting and analysis that proves next actions to be reasonable.

It is expected that harmonized analytical methods on commonly available data such as room sensor temperature and humidity values could provide a way to identify the first steps on energy efficiency measures in ways that could be replicated to larger scales, even city-wide analysis. The three most useful analyses are (1) whether the heating curve is optimal, (2) whether temperature levels between apartments are aligned and (3) what is the level of overheating on both apartments and communal spaces. The three methods together were expected to provide $10-20 \%$ savings on primary energy consumption without additional investment on equipment.

For the sensors, data quality definition was created by implementing some of the ISO 19157 elements and the goal is to create self-explanatory data streams that can be processed live with meaningful results being achieved focusing on the three analyses described in this study. 


\section{Related Work}

Data quality has been the subject of numerous studies, especially for Information Systems. It has been noted though that mainly the focus has been on static data and not sensor or other dynamic data. Specifically, most research has not taken into account the nature of sensor data, including its dynamicity, temporality and heterogeneity [2]. The main exception is the research in the field of geospatial sciences, where the data quality has been included in the program of ISO TC/211 standardization effort as ISO 19157. It is the most comprehensive attempt to describe the data quality and even though it focuses on the geographical data, it could have a wider usage as well. The ISO 19157 has been implemented as DQ_Element in the OGC SensorThings API that is intended to be a generic sensor data model.

The correlation between humidity and $\mathrm{CO}_{2}$ concentration has been studied by Lazovic et al. [3]. Their methodology was based on measurements made with professional handheld measuring devices that had more advanced measuring principles than typical low-power room sensors. Therefore, it was considered to be beneficial for practical use to repeat the study on that part and see whether lower-grade sensors would provide the same results.

\section{Methodology}

The study was made using typical wireless home sensor devices and their recommended calibration methods knowing that the quality of collected data is unknown. It was also known that widely used analytical methods in the field of energy efficiency are hardly based on documented scientific research. Several findings were made to encourage future research on the topics.

The data quality element (DQ_Element) based on the ISO 19157 standard was created to manage quality related metadata of the sensors. In the implementation the following main elements were included:

- DQ_ThematicAccuracy

- DQ_EvaluationMethod

- DQ_ConformanceResult

- DQ_ElementCorrection

DQ_ElementCorrection was not described in the ISO 19157 standard but was included as a placeholder for the compensation function. The term is used more widely in medical science and an example of a paper defines it in the context of calibration process [4]. It is expected that the Element Correction Factor could maintain the compensation function using notation that is compatible with the str_expr -attribute in SymPy -symbolic mathematical library for Python, as part of the Stream Processor concept of Apache Kafka. With this approach the sensor metadata containing the compensation function the streaming values can be corrected in real time.

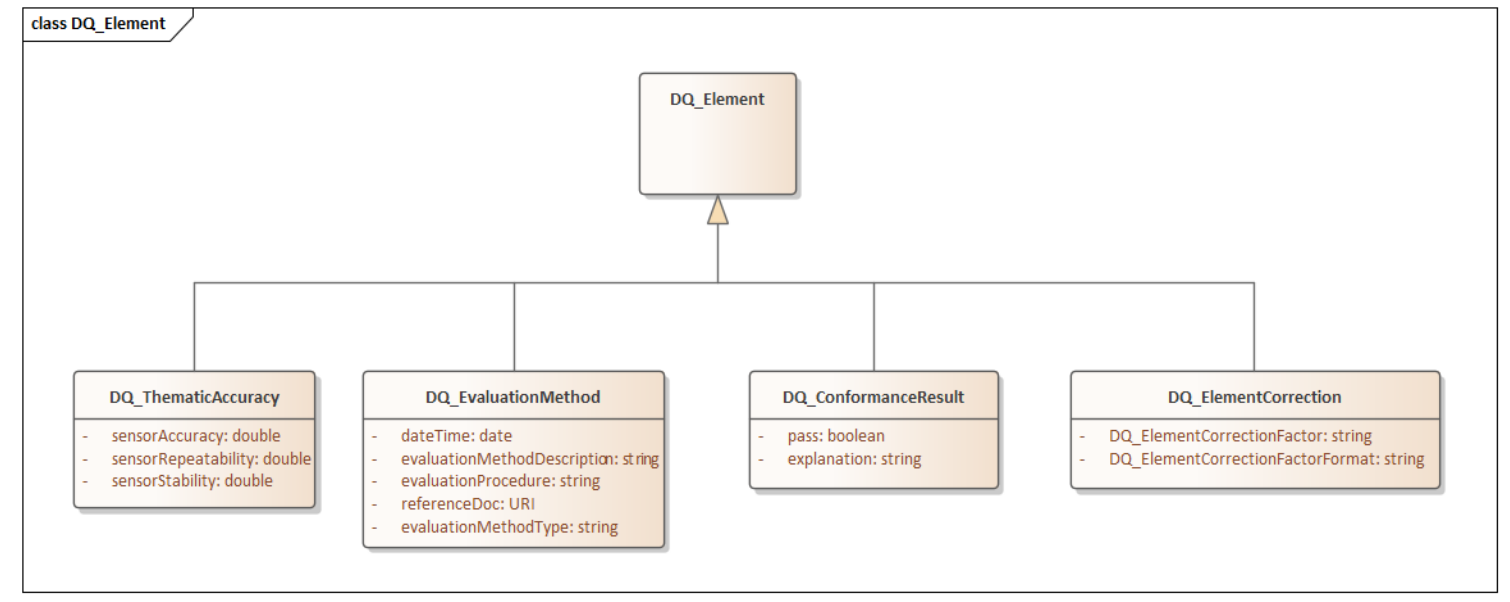

Figure 1. Data Quality Element. 
The process of real time data stream compensation is not the subject of this paper. However, the early results from the data acquisition platform show that the effort put on calibration and compensation is meaningful.

The sensor system was selected and commissioned to collect data to answer the following questions:

Will the indoor temperature remain stable while the outdoor temperature varies?

Apartment buildings are typically not equipped with a building automation system (BAS). In the buildings with water-driven central heating the indoor temperature levels are mainly controlled using the central heating controller and thermometers in each of the radiators. The role of the central heating controller is to control the incoming hot water flow according to the outdoor temperature. The controller adjusts the valve based on a heating curve that is an array of temperature value pairs, linking target water flow temperature with the outdoor air temperature. In simple controllers the array may consist of three value pairs, typically with outdoor temperatures of $-20^{\circ} \mathrm{C}, 0^{\circ} \mathrm{C}$ and +20 ${ }^{\circ} \mathrm{C}$. The following example from Ouman heating controller illustrates the heating curve and its configuration:

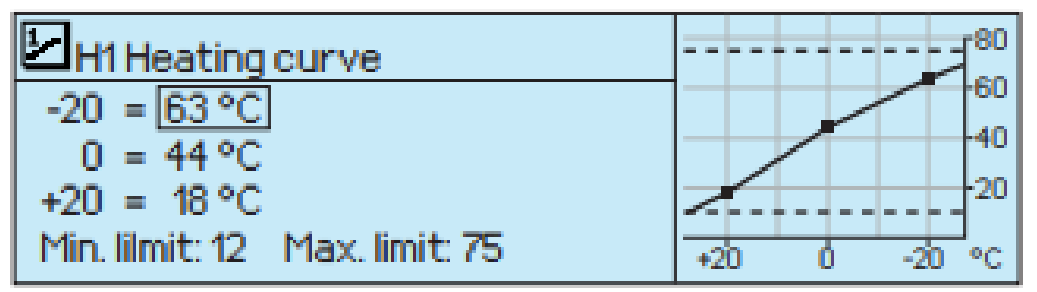

Figure 2. Heating Curve Setup.

To achieve energy efficient heating of buildings the target is to keep the indoor temperature of all the apartments of the house stable and at the same level. So, the indoor temperature should not be affected by outdoor temperature. In order to find out the stability of warming, it has been studied whether the outdoor temperature has an effect on indoor temperatures in the apartments. In the analysis of data, the outdoor temperature values have been divided into 5 Celsius degree bins. For each bin, statistics of indoor temperatures as well as number of samples and mean of outdoor temperatures are computed. The statistics of indoor temperature include median, mean, minimum, maximum values as well as $5 \%$ and $95 \%$ percentile values.

Are the indoor temperatures aligned between the apartments, especially between the first and last ones in the heating circuit?

All the apartments should have the same temperature and this temperature should not change when the outdoor temperature decreases or increases. The heat distribution system in the building contains line valves for each line that can be adjusted to control the hot water flow. Also, the thermometers mounted on radiators tend to gradually wear down over the years and their replacement may be a prerequisite for further adjustments.

Are the $\mathrm{CO}_{2}$ measurements reliable and useful for analysis or can the humidity data provide the same answers?

For this study, statistics of both $\mathrm{CO}_{2}$ and humidity measurements as well as correlations between them during the heating season have been created. Values of $\mathrm{CO}_{2}$ concentration indoors should always be above $400-420$ ppm, which is the outdoor concentration of fresh air in Helsinki, Finland.

What is the percentage of overheating during the heating period and what savings could temperature optimization provide?

The rate of overheating has been studied both in the apartments and in communal spaces of houses. Overheating is computed as positive deviation from recommended temperature. In Finland, 
the recommended temperature in the apartments is $+21{ }^{\circ} \mathrm{C}$ and in communal spaces of houses it is $+17{ }^{\circ} \mathrm{C}$ [5]. To show the deviation median, mean, and $5 \%$ and $95 \%$ percentiles are computed. In this study, only the measurements collected during the heating period are used.

\section{Results}

\section{Q1: Will the indoor temperature remain stable while the outdoor temperature varies?}

To be able to study the relationship between indoor and outdoor temperatures the measurements collected from the apartments of one building during one year have been used. The data collection period was from 24 September 2019 to 24 September 2020. The outdoor temperature is from the nearest Finnish Meteorological Institute (FMI) measurement station. Samples have been averaged over a four-hour interval. During winter 2019-2020 the four-hour average outdoor temperature did not fall below $-7.5^{\circ} \mathrm{C}$ at the used measurement station at all.

Heating season four hour mean statistics of outdoor temperatures from the nearest FMI measurement station are shown in the Table 1 below.

Table 1. Statistics of Heating Season Outdoor Temperature $\left({ }^{\circ} \mathrm{C}\right)$.

\begin{tabular}{cccccccc}
\hline & 2013-2014 & 2014-2015 & 2015-2016 & 2016-2017 & 2017-2018 & 2018-2019 & 2019-2020 \\
\hline mean & 2.3 & 2.6 & 2.2 & 1.0 & 1.1 & 1.9 & 3.5 \\
$\min$ & -18.7 & -15.2 & -23.7 & -19.8 & -20.0 & -18.9 & -7.1 \\
$5 \%$ & -9.7 & -4.9 & -12.2 & -6.9 & -10.0 & -7.7 & -2.2 \\
$50 \%$ & 3.1 & 2.5 & 2.8 & 1.2 & 1.7 & 1.7 & 3.5 \\
$95 \%$ & 9.9 & 9.6 & 10.6 & 7.4 & 10.0 & 10.9 & 9.6 \\
$\max$ & 15.2 & 12.2 & 16.8 & 14.0 & 19.0 & 16.6 & 13.9 \\
\hline
\end{tabular}

As described in the statistics above the minimum of four hour mean temperatures during the last winter was only $-7.1^{\circ} \mathrm{C}$ which is over ten degrees warmer than the usual.

The following table shows the number of times and the ratio of four-hour intervals in which the average outdoor temperature has been below $0{ }^{\circ} \mathrm{C}$ per heating season. This information is meaningful because the lowest setpoint of the heating curve is $-20^{\circ} \mathrm{C}$ and such conditions are getting rare due to the changing climate.

Table 2. Count and Ratio of Sub-0 Outdoor Temperatures during Heating Season.

\begin{tabular}{ccc}
\hline Season & Count & \% \\
\hline $2013-14$ & 283 & 20.9 \\
$2014-15$ & 269 & 19.8 \\
$2015-16$ & 318 & 23.4 \\
$2016-17$ & 454 & 33.5 \\
$2017-18$ & 481 & 35.4 \\
$2018-19$ & 442 & 32.6 \\
$2019-20$ & 161 & 11.9 \\
\hline
\end{tabular}

Table 3. Indoor and Outdoor Temperatures.

\begin{tabular}{ccccccc}
\hline Sensor & {$[\mathbf{- 7 . 5 , - 2 . 5 )}$} & {$[\mathbf{- 2 . 5 , 2 . 5 )}$} & {$[\mathbf{2 . 5 ,} \mathbf{7 . 5})$} & $\mathbf{[ 7 . 5 , 1 2 . 5 )}$ & {$[\mathbf{1 2 . 5 , 1 7 . 5 )}$} & {$[\mathbf{1 7 . 5 , 2 2 . 5 )}$} \\
\hline outdoor & -5 & 0 & 5 & 10 & 15 & 20 \\
FMItem & -3.94 & 0.71 & 4.64 & 10.18 & 15.00 & 19.21 \\
A1 & 22.03 & 22.25 & 22.31 & 23.19 & 24.71 & 26.25 \\
A2 & 20.31 & 20.50 & 20.82 & 21.97 & 24.18 & 26.35 \\
A3 & 22.47 & 22.28 & 22.08 & 22.01 & 22.39 & 23.18 \\
A4 & 20.34 & 20.56 & 20.85 & 21.91 & 24.00 & 25.31 \\
A5 & 19.41 & 19.61 & 19.60 & 20.09 & 21.60 & 22.96 \\
\hline
\end{tabular}


Eng. Proc. 2020, 1, FOR PEER REVIEW

\begin{tabular}{ccccccc} 
A6 & 19.31 & 19.46 & 19.63 & 20.86 & 23.66 & 25.90 \\
A7 & 21.90 & 22.00 & 21.99 & 21.96 & 22.39 & 23.76 \\
median & 20.34 & 20.56 & 20.85 & 21.96 & 23.66 & 25.31 \\
mean & 20.82 & 20.95 & 21.04 & 21.71 & 23.28 & 24.82 \\
min & 19.31 & 19.46 & 19.60 & 20.09 & 21.60 & 22.96 \\
max & 22.47 & 22.28 & 22.31 & 23.19 & 24.71 & 26.35 \\
$5 \%$ & 19.34 & 19.51 & 19.61 & 20.32 & 21.84 & 23.02 \\
$95 \%$ & 22.34 & 22.27 & 22.24 & 22.83 & 24.55 & 26.32 \\
samples & 56 & 419 & 792 & 276 & 450 & 192 \\
\hline
\end{tabular}

The indoor temperatures of the apartments are stable when the outdoor temperature is between -7.5 and $12.5^{\circ} \mathrm{C}$. In the studied building there are two apartments in which the indoor temperature is about $2{ }^{\circ} \mathrm{C}$ lower than the average.

Q2: Are the $\mathrm{CO}_{2}$ measurements reliable and useful for analysis or can the humidity data provide the same answers?

Correlation between $\mathrm{CO}_{2}$ and humidity measurements in sensors of one house. The dataset is collected during the heating season from 1 October 2019 to 15 May 2020.

Table 4. $\mathrm{CO}_{2} / \mathrm{Rh}$ Correlation.

\begin{tabular}{cc}
\hline Sensor & Correlation \\
\hline A1 & 0.51 \\
A2 & 0.50 \\
A3 & 0.21 \\
A4 & 0.50 \\
A5 & 0.17 \\
A6 & 0.57 \\
A7 & 0.30 \\
median & 0.50 \\
\hline
\end{tabular}

Correlation of the $\mathrm{CO}_{2}$ and humidity was computed in $5{ }^{\circ} \mathrm{C}$ temperature bins.

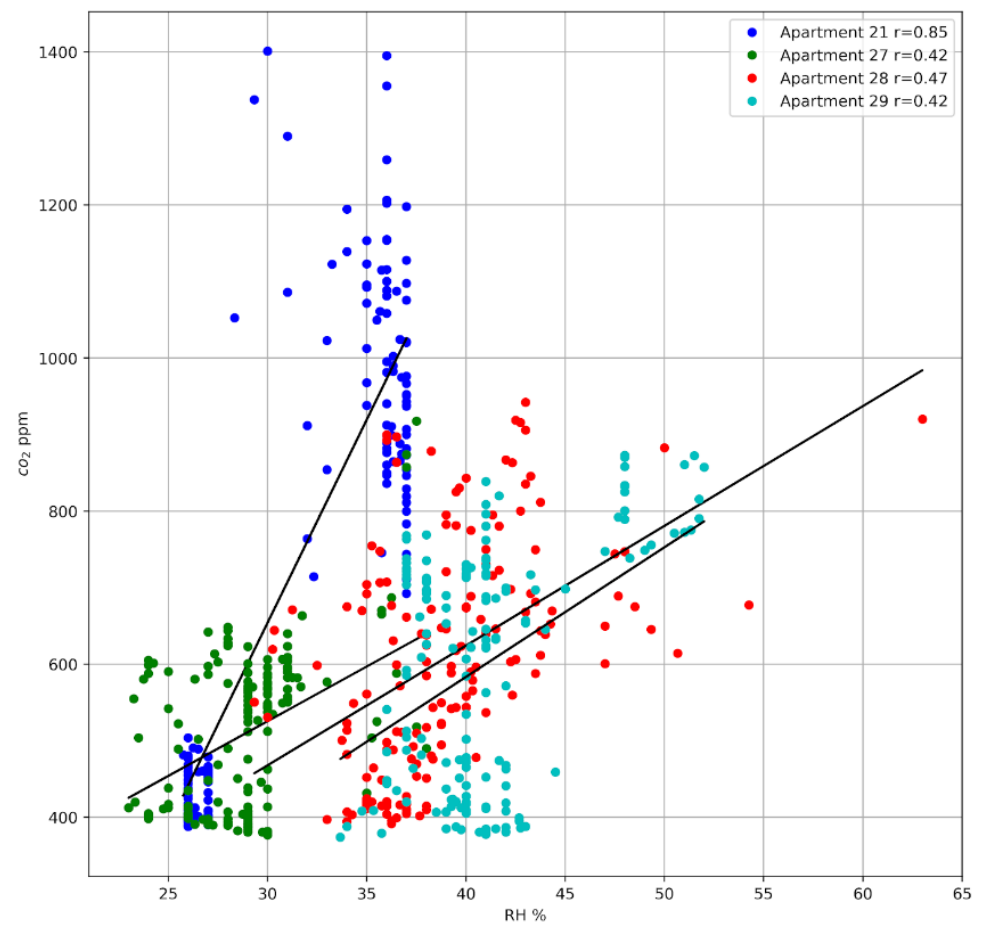


Figure 3. Correlation of $\mathrm{CO}_{2}$ and humidity in four apartments based on one-week measurements.

Statistics of humidity on different outdoor temperatures (data collected from 24 September 2019 to 24 September 2020). Values have been averaged over a four-hour interval.

Table 5. Humidity values and outdoor temperatures.

\begin{tabular}{ccccccc}
\hline Sensor & {$[\mathbf{- 7 . 5 , - 2 . 5 )}$} & {$[\mathbf{- 2 . 5 ,} \mathbf{2 . 5})$} & $\mathbf{[ 2 . 5 , 7 . 5 )}$ & {$[\mathbf{7 . 5 , 1 2 . 5 )}$} & {$[\mathbf{1 2 . 5 , 1 7 . 5 )}$} & {$[\mathbf{1 7 . 5 , 2 2 . 5 )}$} \\
\hline outdoor & -5 & 0 & 5 & 10 & 15 & 20 \\
t2m & -3.9 & 0.7 & 4.6 & 10.2 & 15.0 & 19.2 \\
A1 & 25.5 & 29.8 & 33.3 & 43.1 & 49.7 & 49.5 \\
A2 & 30.7 & 32.9 & 34.7 & 39.8 & 44.7 & 45.3 \\
A3 & 23.6 & 27.3 & 30.5 & 39.3 & 50.9 & 53.8 \\
A4 & 35.0 & 36.9 & 40.6 & 44.8 & 46.8 & 48.6 \\
A5 & 31.0 & 36.1 & 40.4 & 48.2 & 56.2 & 58.3 \\
A6 & 31.6 & 36.7 & 41.3 & 48.9 & 54.9 & 57.9 \\
A7 & 28.3 & 31.9 & 34.6 & 41.9 & 50.0 & 51.9 \\
median & 30.7 & 32.9 & 34.7 & 43.1 & 50.0 & 51.9 \\
mean & 29.4 & 33.1 & 36.5 & 43.7 & 50.5 & 52.2 \\
min & 23.6 & 27.3 & 30.5 & 39.3 & 44.7 & 45.3 \\
max & 35.0 & 36.9 & 41.3 & 48.9 & 56.2 & 58.3 \\
$5 \%$ & 24.2 & 28.0 & 31.4 & 39.5 & 45.3 & 46.3 \\
$95 \%$ & 34.0 & 36.9 & 41.1 & 48.7 & 55.9 & 58.2 \\
count & 56 & 419 & 792 & 276 & 450 & 192 \\
\hline
\end{tabular}

The following table provides the values of $\mathrm{CO}_{2}$ sensors in PPM during the heating season.

Table 6. $\mathrm{CO}_{2}$ concentration and outdoor temperatures.

\begin{tabular}{ccccccc}
\hline Sensor & {$[-\mathbf{7 . 5}, \mathbf{- 2 . 5})$} & {$[\mathbf{- 2 . 5 , 2 . 5 )}$} & {$[\mathbf{2 . 5 , 7 . 5 )}$} & $\mathbf{[ 7 . 5 , 1 2 . 5 )}$ & {$[\mathbf{1 2 . 5 , 1 7 . 5 )}$} & {$[\mathbf{1 7 . 5 , 2 2 . 5})$} \\
\hline outdoortemp & -5 & 0 & 5 & 10 & 15 & 20 \\
FMI & -3.9 & 0.7 & 4.6 & 10.2 & 15.0 & 19.2 \\
A1 & 533.0 & 597.3 & 585.1 & 582.9 & 430.4 & 296.2 \\
A2 & 634.6 & 548.8 & 518.0 & 505.7 & 471.3 & 463.4 \\
A3 & 637.6 & 566.6 & 538.4 & 561.3 & 561.6 & 517.3 \\
A4 & 790.2 & 710.6 & 655.0 & 564.8 & 520.6 & 466.6 \\
A5 & 569.2 & 562.9 & 558.8 & 564.9 & 505.3 & 486.3 \\
A6 & 365.1 & 399.7 & 424.4 & 504.5 & 415.4 & 518.9 \\
A7 & 560.4 & 544.2 & 534.0 & 527.2 & 487.3 & 453.6 \\
median & 569.2 & 562.9 & 538.4 & 561.3 & 487.3 & 466.6 \\
mean & 584.3 & 561.4 & 544.8 & 544.5 & 484.6 & 457.5 \\
min & 365.1 & 399.7 & 424.4 & 504.5 & 415.4 & 296.2 \\
max & 790.2 & 710.6 & 655.0 & 582.9 & 561.6 & 518.9 \\
5\% & 415.4 & 443.0 & 452.5 & 504.9 & 419.9 & 343.5 \\
95\% & 744.4 & 676.6 & 634.1 & 577.5 & 549.3 & 518.4 \\
samples & 56 & 419 & 792 & 276 & 450 & 192 \\
\hline
\end{tabular}

Q3: What is the cumulative amount of overheating during the heating period and what savings can optimization provide?

Overheating measured in Celsius degrees in the apartments of one house. Measurements collected during the heating period from 1 October 2019 to 15 May 2020 are used.

The following table provides statistics of positive deviations of temperature i.e., overheating. Values below recommended temperature values are converted to recommended values. This is due to 
computation of possible saving \% value in energy consumption (last column in table below). So, by adjusting the indoor temperature to recommended value savings up to $6.5 \%$ per apartment is possible.

Table 7. Overheating in apartments.

\begin{tabular}{cccccc}
\hline Sensor & $\mathbf{5 \%}$ & $\mathbf{9 5} \%$ & Mean & Median & Mean Save\% \\
\hline A1 & 0.02 & 2.85 & 1.33 & 1.27 & 6.52 \\
A2 & 0.00 & 1.65 & 0.25 & 0.00 & 1.25 \\
A3 & 0.50 & 2.20 & 1.15 & 1.03 & 5.71 \\
A4 & 0.00 & 3.07 & 0.52 & 0.00 & 2.51 \\
A5 & 0.00 & 0.00 & 0.00 & 0.00 & 0.00 \\
A6 & 0.00 & 0.00 & 0.01 & 0.00 & 0.06 \\
A7 & 0.45 & 1.50 & 0.99 & 1.00 & 4.94 \\
Mean & 0.14 & 1.61 & 0.61 & 0.47 & 3.00 \\
\hline
\end{tabular}

The following table provides a similar overview in the case of communal spaces. The higher savings potential is due to the recommendation of lower base temperatures.

Table 8. Overheating in communal spaces.

\begin{tabular}{cccccc}
\hline Sensor & $\mathbf{5 \%}$ & $\mathbf{9 5 \%}$ & Mean & Median & Mean Save\% \\
\hline B1 & 0.37 & 4.33 & 1.79 & 1.40 & 8.59 \\
B2 & 2.37 & 5.13 & 3.42 & 3.30 & 16.01 \\
B3 & 4.30 & 5.50 & 4.83 & 4.73 & 21.94 \\
B4 & 3.70 & 5.60 & 4.57 & 4.52 & 20.85 \\
B5 & 2.13 & 5.00 & 3.41 & 3.30 & 15.97 \\
B6 & 4.13 & 6.20 & 4.88 & 4.65 & 22.10 \\
B7 & 3.40 & 4.80 & 3.90 & 3.77 & 18.10 \\
Mean & 2.91 & 5.22 & 3.83 & 3.67 & 17.65 \\
\hline
\end{tabular}

In the pilot location where the average weekly heating energy consumption during the heating season is $11 \mathrm{MWh}$, it is estimated that on average, $75 \%$ of the floor area is dwellings and the remaining $25 \%$ is communal areas, such as storage spaces, laundry rooms and bike storages. With these assumptions, the savings potential is estimated to be $0.73 \mathrm{MWh}$ on the weekly basis, equaling to about $46.00 €$ as calculated with the current energy list prices of Helen Ltd. (Helsinki, Finland).

\section{Discussion}

Smart home sensors are oftentimes proposed as an entry level solution to improve energy efficiency, connected with advanced data-driven services. The service providers are not usually transparent on what the analytical methods actually are and the benefits to the consumers remain unclear. In this study the potential of optimization was narrowed into three main issues and the expectation was that $10-20 \%$ of savings in primary energy were achievable.

The results show that this is somewhat true. While no actual optimization tasks like replacement of thermometers were made, already the potential in recognizing the overheating situations are significant. Especially in the communal spaces the potential is significant, since typically such spaces are set to same temperatures than the apartments.

The question on correlation between the humidity and $\mathrm{CO}_{2}$ concentration was raised as research question due to the fact that the sensor with $\mathrm{CO}_{2}$ sensing capability was about $40 €$ more expensive than a normal room sensor. It was also suspected that the quality of $\mathrm{CO}_{2}$ data was lower than with the other measurements due to the low-cost and low-power sensing component. In the actual analysis it was even difficult to complete the work since the data was so bad: several sensors provided values lower than the fresh air in outdoors even though all of them were calibrated according to the manufacturer's advice. In practice it is unlikely that such advice is even always followed or that it is 
not feasible to do so e.g., because of large quantity of sensors to be installed. Another issue with the correlation is also the nature of humidity in home environment: it can quickly rise because of using shower or cooking. With high number of sensors and longer trend of datapoints the correlation would be closer to what was achieved in the earlier study [3]. As a conclusion however, it can be said that the $\mathrm{CO}_{2}$ sensor capability does not add significant value in normal home settings and should be avoided unless there is a reason to do so. This study did not contain analysis of ventilation, but even in that case it is assumed that the humidity values would provide as useful input for the analysis than $\mathrm{CO}_{2}$ concentration.

The analysis of cumulative potential of energy savings was based on "common knowledge" that one-degree change in room temperature equals with five percentage change in energy consumption. This information has been widely used in training of energy specialists and materials created for tenants to motivate them to make sustainable choices in their living. The origin of this information was traced back to the HVAC laboratory of VTT, the Research Institute of Finland where the ratio has been defined using simulations. It wasn't however known if this has ever been documented or published as a scientific article. Such quick and easy indicators have an increasing importance when the energy performance of facilities is becoming more closely followed.

In Finland, many of the tuning and optimization methods of HVAC controls are based on processes that require certain temperature levels outdoors. As an example, the lower setpoint on the basic heating controllers is at $-20^{\circ}$ Celsius. As shown in Table 1 , such winters are becoming rare and in the past seven years only in two winters the temperature has been below that level. Warm winters also increase the risks of issues caused by increasing humidity that typically have been compensated by increasing the temperature of water in district heating system, attempting to dry the air. Because of this, new ways to set the heating curves are needed and with continuous monitoring instead of one-time tuning, the building can remain optimized and maintain the level of comfort the tenants expect.

Funding: This research was funded by European Union Horizon 2020 program in mySMARTLife project, grant number 731297. The data collection pilots were part of the European Union European Regional Development Fund project 6Aika Climate Friendly Housing Companies.

Conflicts of Interest: The authors declare no conflict of interest.

\section{References}

1. C. of Helsinki. The Carbon-Neutral Helsinki 2035 Action Plan; Publisher: City, Country, Year.

2. Rodriguez, C.; Servigne, S. Sensor Data Quality for Geospatial Monitoring Applications. In Proceedings of the AGILE, 15th Internationale Conference on Geographic Information Science, Avignon, France, 24-27 April 2012; pp. 24-27.

3. Lazovic, I.; Stevanovic, Z.; Jovasevic-Stojanovic, M.; Zivkovic, M.; Banjac, M. Impact of $\mathrm{CO}_{2}$ concentration on indoor air quality and correlation with relative humidity and indoor air temperature in school buildings in Serbia. Therm. Sci. 2016, 20 (Suppl. 1), 297-307.

4. Plato, P.; Miklos, J. Production of element correction factors for thermoluminescent dosimeters. Health Phys. 1985, 49, 873-881.

5. STM. Asumisterveysohje; 2003.

Publisher's Note: MDPI stays neutral with regard to jurisdictional claims in published maps and institutional affiliations.

(C) 2020 by the authors. Submitted for possible open access publication under the terms and conditions of the Creative Commons Attribution (CC BY) license (http://creativecommons.org/licenses/by/4.0/). 